\title{
DIFERENÇA E REPETIÇÃO NO NÓSTOS DE ODISSEU: O DISCURSO DE EURICLEIA PARA O MENDIGO ESTRANGEIRO (OD. XIX, 363-381) ${ }^{1}$
}

\author{
Rafael Guimarães Tavares da Silva* \\ Recebido em: 14/01/2018 \\ Aprovado em: 06/04/2018
}

RESUMO: Partindo de considerações sobre a importância de personagens "menores" para o desenrolar da Odisseia (como é o caso de Eumeu e Euricleia), o presente artigo atenta para uma série de nuances presentes no canto XIX e reflete sobre a forma anelar segundo a qual esse trecho se desenvolve, em torno ao reconhecimento de Odisseu por sua velha serva. Contrariando a leitura tradicional dessa passagem, defendemos que esse reconhecimento não apenas é desejado por Odisseu, mas é motivado - de uma perspectiva interna à lógica da narrativa - pela necessidade de restabelecimento das bases fundamentais para que o rei ausente readquira o seu nome e a sua história antes de readquirir o seu poder de fato.

PALAVRAS-CHAVE: Odisseia; cena de reconhecimento; Odisseu; Euricleia.

\section{DIFFERENCE AND REPETITION IN THE NOSTOS OF ODYSSEUS: EURYKLELA'S SPEECH TO THE FOREIGN BEGGAR (OD. 19.363-381)}

* Doutorando do Programa de PósGraduação em Estudos Literários, Universidade Federal de Minas Gerais. Bolsista da Coordenação de Aperfeiçoamento de Pessoal de Nível Superior, CAPES. gts.rafa@hotmail.com

\footnotetext{
ABSTRACT: Departing from considerations about the importance of "minor" characters to the development of the Odyssey (as it is the case of Eumaeus and Eurycleia), the present paper gives attention to a series of nuances present in the Book XIX and reflects about the ring form according to which this excerpt develops itself, around the recognition

${ }^{1}$ Agradecemos profundamente a generosidade demonstrada pelo(a)s pareceristas anônimo(a)s da Classica. Levamos em conta as suas indicações, comentários e críticas sempre que nos pareceu possível fazê-lo com vantagens à clareza expositiva e informativa do texto. Aquilo que não foi incorporado, contudo, será levado em conta por nossas futuras reflexões sobre esses temas.
} 
of Odysseus by his old servant. Going against the traditional interpretation of this passage, we defend that this recognition is not only desired by Odysseus, but is motivated - from a perspective internal to the narrative - by the necessity of reestablishing fundamental bases for the absent king to reacquire his name and history before reacquiring his power of fact.

KEYWORDS: Odyssey; Recognition scene; Odysseus; Eurycleia.

importância das cenas de reconhecimento para o enredo da Odisseia foi notada na
própria Antiguidade, como o tratamento que Aristóteles dispensa à questão bem o
indica. Segundo o filósofo: "a Odisseia é complexa, pois é por completo reconhecimento [Odýsseia peplegménon (anagnórisis gàr diólou)]" (Poet. 1459b15, trad. nossa). Desde então, novas gerações de leitores e intérpretes da obra não deixaram de considerar as motivações e implicações envolvidas no emprego de tal recurso para o desenvolvimento intrincado de um dos poemas fundamentais da literatura universal.

Duas ideias básicas estão relacionadas ao tema do reconhecimento na Odisseia. Em primeiro lugar, uma vez que se trata de um poema de nóstos - ou seja, de retorno para casa após muitos anos de ausência -, o motivo do reconhecimento daquele que retorna é um elemento imprescindível, posto que a ignorância sobre a identidade do herói desempenha um papel decisivo nesse tipo de enredo (Duarte, 2012, p. 99). Em segundo lugar, todo reconhecimento envolve um confronto do status quo com uma nova situação até então ignorada, suscitando a possibilidade do estabelecimento de uma nova ordem ou, como no caso de Odisseu, da restauração de uma ordem anterior. Nas palavras de Gainsford (2003, p. 54):

Todos os vários tipos de restauração combinados - geográfica, política e familiar - constituem juntamente a narrativa de nóstos e, para generalizar, a própria Odisseia. A reintegração que Odisseu busca é a reintegração com a casa como um todo; ele age como a pedra angular para a integridade e continuidade do ôkkos. Por conseguinte, temos uma relação bipolar: por um lado, Odisseu, e por outro, a família inteira, enquanto uma entidade incorporada que depende dele como fonte de segurança, como fonte patriarcal de genealogia, e como símbolo que lhe oferece a sua identidade (não se trata de qualquer família, mas da família de Odisseu). ${ }^{2}$

Com certeza é preciso ressaltar que na "bipolaridade" dessa relação, Odisseu depende tanto da fidelidade dos membros do seu ôkkos, quanto cada um desses membros depende do

\footnotetext{
${ }^{2}$ Tradução nossa. No original: "All the various kinds of restoration combined - geographical, political and familial - together constitute the nostos-narrative and, to stretch a point, the Odyssey itself. The reintegration that Odysseus seeks is reintegration with the household as a whole; he acts as a keystone to the integrity and continuity of the oikos. We therefore have a bipolar relationship: on one side, Odysseus, and on the other, the entire family, as a corporate entity which depends on him as a source of safety, as a patriarchal source of genealogy, and as a symbol that gives it its identity (it is not just any family, it is the family of Odysseus)." (Gainsford, 2003, p. 54).
} 
retorno do patriarca. ${ }^{3}$ Assim sendo, o papel de Eumeu e Euricleia, por exemplo, personagens compreensíveis como "menores" no contexto da Odisseia, ganha uma importância insólita em narrativas helênicas (ainda mais no âmbito do período arcaico). Embora o momento em que Odisseu triunfa sobre os pretendentes de Penélope assuma os ares de uma epifania divina, é preciso ressaltar que "ele difere de uma [epifania] justamente na medida em que só se faz possível com o apoio de certos cúmplices humanos, cuja ajuda é assegurada numa série de cenas privadas de reconhecimento que estruturam a segunda metade do poema." (Murnaghan, 1987, p. 14). ${ }^{4}$

A importância das cenas em que essas personagens "menores" reconhecem o seu antigo rei, Odisseu, na figura do mendigo recém-chegado, é ampliada ainda por dois fatores. Por um lado, é preciso ressaltar o nível de desordem que a impotência juvenil de Telêmaco e a inatividade constrangida de Penélope suscitaram no interior do ambiente doméstico. Ao que tudo indica, se o ôkkos de Odisseu não tivesse contado com a diligência de servos dedicados, os seus recursos certamente estariam ainda mais dilapidados. ${ }^{5}$ Por outro lado, como as relações entre o patrão e a sua criadagem - ou, melhor dizendo, os seus $\operatorname{escravos}^{6}$ - não se baseiam em liames de sangue, é evidente que elas estão muito mais expostas ao risco de virem a se romper diante de situações desfavoráveis e excessivamente tensas, como é o caso em Ítaca. ${ }^{7}$ Nesse sentido, o teste a que Odisseu submete cada um dos seus servos, a fim de verificar a sua fidelidade, justifica-se de maneira ainda mais clara. $O$ tempo da vingança de

\footnotetext{
${ }^{3}$ A questão é tratada com o discernimento necessário por Murnaghan (1987, p. 28): “[...] it is possible to read the distribution of Odysseus' recognitions in another way, to see it as a means of highlighting his dependence on the loyalty of his social subordinates, a loyalty that is far from automatic. The tense moment of real danger to Odysseus' whole project created by Eurycleia's recognition of him dramatizes how much he needs to be able to rely on her and on others like her."

${ }^{4}$ Tradução nossa. No original, a frase inteira é a seguinte: "But while Odysseus' moment of triumph over the suitors resembles a divine epiphany, it also differs from one in that it is only possible with the aid of certain human accomplices, whose help is secured in a series of private scenes of recognition that structure the second half of the poem.” (Murnaghan, 1987, p. 14).

${ }^{5}$ A formulação é colocada por Austin (1975, p. 165-6): "Eurykleia and Eumaios, in particular, have dramatic parts to play precisely because of their master's abdication. It is the servants, not the masters, who retain some vestige of order in the face of general anarchy. While the one does what he can to preserve the state, the other plays her parallel part in the domestic economy of the palace."

${ }^{6}$ Acerca da estrutura escravista do poema, cf. Thalmann, 1998. Acerca da representação de Euricleia e Eumeu especificamente, cf. Thalmann, 1998, p. 78-100.

${ }^{7}$ Concordamos com a formulação de Murnaghan por meio da qual tais pontos são abordados: “The recognition scenes that cluster around the defeat of the suitors involve the recreation of more difficult relationships with people to whom Odysseus is not related by blood: his loyal servants, Eurycleia, Eumaeus, and Philoetius, and his wife Penelope. Because these relationships are not based on any natural tie but are artificial social constructs, their continuity over time is genuinely subject to question as the continuity of the indissoluble kinship of father and son is not. Thus the aspects of Odysseus' identity affirmed by his relations with these figures are more seriously threatened by his absence than is his identity as son of Laertes or father of Telemachus." (Murnaghan, 1987, p. 27). E, na sequência
}

Classica, v. 31, n. 1, p. 9-24, 2018 
Odisseu não há de se fazer esperar e, na sequência, será preciso que o herói disponha de critérios anteriormente estabelecidos para diferenciar, no interior do seu ôkos, o joio do trigo.

Diante de todos esses argumentos, é possível afirmar que estudos mais detidos de entrechos nos quais figuram essas personagens "menores" podem trazer dados interessantes para um novo esboço da figura de Odisseu e até mesmo para uma interpretação diferenciada do poema como um todo. Nesse sentido, somos da opinião que a personagem de Euricleia apresente uma caracterização de peso e de valor considerável na epopeia. Em primeiro lugar, podemos entendê-la (bem como a Eumeu), a partir da perspectiva da sua contínua submissão voluntária a um mestre ausente, como alguém no interior de uma relação que parece transcender os meros liames sociais da escravidão: tudo se passa como se tal relação efetivamente se cumprisse numa união socialmente equivalente e involuntária de membros familiares. ${ }^{8}$ Em segundo lugar, a relação privilegiada da qual Euricleia desfruta para com Odisseu fica evidente quando se leva em conta o que afirma Adriane Duarte (2012, p. 119, n. 35):

Euricleia, vale lembrar, também é chamada afetuosamente pelo herói de "mãezinha" (Od., XIX, 482, 500: maîa), tendo desempenhado de fato funções maternais como quando acolhe o recém-nascido em seus braços e o leva a seu avô, para que lhe dê o nome (Od., XIX, 399-404).

Algo análogo poderia ser sugerido também para a relação afetuosa que Euricleia apresenta perante Telêmaco, filho de Odisseu (Werner, 2011, p. 14), e Laerte, o seu pai (Thalmann, 1998, p. 78). Justificada a motivação para a escolha de especulações em torno a essa personagem, resta-nos, contudo, circunscrever um entrecho que seja particularmente característico da sua atuação em toda a Odisseia. Movidos por esse intuito e desejando ainda aproveitar para esclarecer uma cena que tem recebido leituras e interpretações bastante variadas (além de críticas frequentemente acerbas), escolhemos tratar um discurso de Euricleia que apresenta um caráter insólito. Trata-se do entrecho em que, depois de ser selecionada por Penélope para limpar os pés do hóspede, a serva se dirige a ele no grande salão (Od. XIX, 363-381).

Antes, contudo, de iniciarmos a análise mais detida desse trecho, gostaríamos de evocar a importância de um recurso poético típico do período arcaico que ficará evidente na nossa leitura. Trata-se da "composição em anel”, referida também como ring-composition. Esse modo de estruturação típico da narrativa poética oral talvez possa ser compreendido como relacionado a uma concepção de mundo (espaço-temporal) diversa daquela que se pauta pela moderna ideia de progresso: de modo diverso, uma estrutura anelar avança circularmente e

do argumento, completa: "But the relationship of master and servant is permanently unequal in status and, on the part of the servants, or more properly slaves, originally involuntary."

${ }^{8}$ Nas palavras de Murnaghan (1987, p. 28): "In addition, the Odyssey makes sense of the continued voluntary submission of unrelated subordinates by assimilating these relationships to the socially equal and involuntary relationships of kinship. As they recognize Odysseus and are recognized by him, the poem suggests that Eurycleia and Eumaeus are more like relatives than like servants." 
acaba retornando ao ponto donde partira a princípio. ${ }^{9}$ Ainda que tal concepção não anule a mudança e o desenvolvimento como possibilidades do devir, ela oferece a estrutura básica por meio da qual o acontecimento dessa mudança vem a ser compreendido. Conforme Austin (1975, p. 131):

Em Homero, a ring-composition figura de modo proeminente como um artifício para emoldurar um discurso, uma cena, um livro e até mesmo um poema, tal como nos livros I e XXIV da Ilíada, que temática e estruturalmente equilibram um ao outro. Os estudiosos viram nessa técnica a expressão verbal das simetrias da arte Geométrica, ou as conveniências formais para se estruturar um poema oral longo. Quando olhamos de perto, contudo, descobrimos que a ring-composition é na verdade um modo de vida. [...] As fórmulas para emoldurar discursos homéricos e os pontos de equilíbrio para as cenas homéricas reproduzem, à sua maneira, um traço distintivo da organização social homérica. ${ }^{10}$

Veremos em breve como esse recurso se articula na cena de que nos ocuparemos a seguir. O encontro em que a serva Euricleia é convocada por Penélope para lavar os pés do mendigo estrangeiro é emoldurado por duas cenas de diálogo entre o mendigo e a própria Penélope, de modo que poderíamos falar de ring-composition também para a estruturação de grande parte do canto XIX. Contentemo-nos, apesar disso, em oferecer por ora uma descrição do quadro que precede o discurso de Euricleia.

Penélope e o mendigo conversam de maneira íntima nos salões, em meio às servas que terminam de arrumar a bagunça deixada pelo banquete daquele dia. ${ }^{11} \mathrm{~A}$ julgar pelo

\footnotetext{
${ }^{9}$ Para um tratamento transcultural da ideia sobre "ring composition", cf. Beard, 2007. No início do seu livro, a autora afirma: "The minimum criterion for a ring composition is for the ending to join up with the beginning. [...] The linking up of starting point and end creates an envelope that contains everything between the opening phrases and the conclusion. The rule for closing the ring endows the work with unity [...]." (Beard, 2007, p. 1).

${ }^{10}$ Tradução nossa. No original: "In Homer too, ring-composition figures prominently as a device for framing a speech, a scene, a book, and even to frame the poem, as Books 1 and 24 of the Iliad thematically and structurally balance each other. Scholars have seen in this technique the verbal expression of the symmetries of Geometric art, or the formal conveniences for structuring a long oral poem. When we look close, however, we find ring-composition to be indeed a way of life. [...] The framing formulas for Homeric speeches, and the balancing panels for Homeric scenes, reproduce in their way a distinctive feature of Homeric social organization.” (Austin, 1975, p. 131).

${ }^{11}$ Penélope não está a sós com o mendigo, ao contrário do que afirma Austin (1975, p. 217): "Nausikaa had once been concerned about the propriety of being seen with a stranger on the city streets. But propriety is stretched a good deal further in Ithaka. The queen is alone with a beggar late at night." (Austin, 1975, p. 217). A passagem de $O d$. XIX, 60-4 descreve claramente a situação. Além disso, tal entendimento é reforçado pela passagem que começa a partir do v. 317. Bollack (2001, p. 239) compreendeu melhor a passagem: «Les servantes sont dans la salle; il n'y a pas seulement Euryclée. »
} 
desenrolar da ação, é possível que Penélope e Odisseu já tenham de fato se reconhecido ao longo da sua primeira conversa, embora a reticência do poema em afirmá-lo claramente - contrariando o seu expediente habitual - dê margem para as duas interpretações. Nos últimos tempos, a controvérsia sobre esse ponto tem sido eventualmente animada, com estudos propondo algo desde um reconhecimento quase imediato (ainda que algumas vezes se fale de "inconsciente", justamente para ressalvar uma parte da reticência do próprio texto homérico), enquanto outros falam de "alguma forma de reconhecimento". ${ }^{12}$

Nesse sentido, embora vislumbremos no episódio a possibilidade para uma interpretação como a de Bollack (que citamos a seguir), acreditamos ser necessário modalizá-la:

Se retivermos as implicações de um não-dito que se precisa, Odisseu extrai um sentido não explicitado. Ora, a extração desse sentido fornece a significação última e intencional dos dois encontros diferidos dos esposos no canto XIX (96-316 e 505-599), que, no primeiro sentido do termo, se reconheceram - como poderiam não tê-lo feito? (Bollack, 2001, p. 237). ${ }^{13}$

Não compartilhando da certeza com que o autor de tais palavras as escreve, deixemos a questão aberta, a fim de manter a dubiedade mantida pelo próprio poema. Na sequência, depois que Penélope oferece ao sensato mendigo uma cama para dormir e, antes, um banho a ser dado por uma das suas jovens servas, ele recusa orgulhosamente tais ofertas, mas aceita o lava-pés no caso de haver uma serva anciã, sempre devotada e tão sofrida quanto ele mesmo. Penélope evoca a antiga ama de Odisseu e a chama para fazer o que o hóspede requisitava. A bem-ajuizada anciã, que estava sentada por ali, levanta-se e vem até o mendigo a fim de cumprir o que Penélope lhe ordenara (Od. XIX, 357).

\footnotetext{
${ }^{12}$ Recorramos aqui à nota em que Duarte (2012, p. 147, n. 56) revisita essa série de artigos e emite o seu juízo sobre os mesmos: "Harsh (1950) defende que Penélope reconheceu Odisseu na entrevista do canto XIX, mas não o revelou abertamente por receio de que suas criadas contassem aos pretendentes. Ao pedir que o hóspede descreva as vestes que Odisseu portava em seu encontro, ela estaria de fato testando-o. Amory (1963) sugere que o reconhecimento tenha se dado no inconsciente e que Penélope tenha colaborado com Odisseu intuitivamente. Recentemente Vlahos (2011), retomando Harsh, defende que o sonho de Penélope e a sugestão da prova do arco são parte de uma conversa criptográfica do casal para iludir as servas. Essas leituras são problemáticas, já que não são respaldadas pelo texto." Contudo, seria possível mencionar uma leitura recente, fortemente "respaldada pelo texto", em que se sugere alguma forma de reconhecimento precoce de Odisseu por Penélope: trata-se do livro de Levaniouk (2011). Trabalhando com o poder evocativo do discurso mítico em diálogos representados por Homero, a autora analisa a conversa de Penélope com o mendigo, no canto XIX, sugerindo que haveria alguma forma de reconhecimento por parte de Penélope a partir do v. 204 (Levaniouk, 2011, p. 22-35).

${ }^{13}$ Tradução nossa. No original: «Si l'on retient les implications d'un non-dit qui se précise, Ulysse saisit un sens non explicité. Or la saisie de ce sens fournit la signification ultime et intentionelle des deux rencontres différées des époux dans le chant XIX (96-316 et 505-599), qui, dans le sens premier du terme, se sont reconnus - comment pourraient-ils ne pas le faire ? » (Bollack, 2001, p. 237).
} 
Diante desse quadro, não podemos concordar com a sugestão de Austin (1975, p. 217), que, partindo erroneamente do pressuposto de que Penélope estaria sozinha com o mendigo no salão, dá a entender que Odisseu teria recusado o banho pelas jovens servas a fim de evitar que elas entrassem no recinto e vissem a sua senhora sozinha com um homem à noite. Nesse sentido, ainda segundo Austin, a escolha de uma "velha serva" não teria sido tomada voluntariamente por Odisseu, mas somente para apontar uma saída decorosa ao constrangimento no qual os dois se encontravam naquele salão a sós. Discordamos de todas essas suposições, na medida em que o narrador da Odisseia afirma claramente que Penélope não estava sozinha com o mendigo no salão (Od. XIX, 60-4, reiterado em 103). Nesse sentido, podemos compreender o desejo manifestado por Odisseu de ter os pés lavados por uma "velha serva" aberto à interpretação de que ele teria de fato planejado se aproximar da sua antiga ama, Euricleia. Soma-se às razões anteriores o fato de que, como Euricleia estava sentada no próprio salão, Odisseu já a teria visto anteriormente - entre outras possíveis, embora não prováveis, servas anciãs - tendo tido, portanto, todas as informações necessárias para evitar a escolha de alguém que pudesse reconhecê-lo (caso quisesse evitar esse reconhecimento).

Alguém poderia, contudo, querer contrapor-se à nossa leitura por meio do entrecho de Od. XIX, 388-91, no qual é afirmado que Odisseu teria se sentado longe da lareira, em meio à penumbra, temendo que a sua antiga ama tocasse a sua cicatriz e revelasse as suas ações. Tal é a argumentação, por exemplo, adotada por de Jong. ${ }^{14}$ Uma leitura alternativa desses versos, contudo, não indica que Odisseu temesse ser reconhecido por Euricleia, mas sim que - vindo a ter a cicatriz tocada e a sua identidade reconhecida pela ama - as suas ações fossem reveladas para as demais pessoas presentes no salão. Parece possível sugerir que ele não hesita perante a perspectiva de ser reconhecido por sua serva, embora tema a possibilidade de que ela fizesse o seu reconhecimento de forma pública. ${ }^{15}$ Nesse sentido, Odisseu poderia ser compreendido como o responsável pela situação em que se encontra: com efeito, parece pouco coerente com uma personagem capaz de autocontrole e astúcia consideráveis em suas ações desde o seu retorno a Ítaca - e em muitas ocasiões relatadas antes pela Odisseia - que ele não seja capaz de estimar as consequências das suas palavras quando pede que uma serva anciã lhe lave os pés. Reiteremos que Euricleia estava sentada no salão e que, provavelmente, era a única serva antiga então presente. ${ }^{16}$ Além disso, talvez valha

\footnotetext{
14 “'Odysseus' attempt not to be recognized (390-1) and his shocked reaction when he is nevertheless recognized (479-90) make it clear that his request for an old servant is in no way intended to result in a reunion with Euryclea." (De Jong, 2001, p. 475).

${ }^{15}$ A questão é colocada por Ahl e Roisman (1996, p. 233) em termos com os quais estamos de acordo: "As Odysseus prepares to be bathed, he again arranges the lighting carefully. He sits facing away from the hearth for fear not that Eurycleia will recognize him by an old hunting scar but that she will make her recognition public (19.391). Her words and her demeanor show she is loyal. But it has been established that the maids are on the suitors' side and that Penelope has mixed feelings." ${ }^{16}$ É praticamente impossível que Odisseu, já estando no salão, não tivesse visto e identificado Euricleia desde que as servas lá entraram para organizar a bagunça do banquete, a partir de Od. XIX,
} 
a pena lembrar que o próprio herói já fora o responsável pelo seu reconhecimento na corte feácia, quando pedira para Demódoco cantar "a glória de Odisseu no cavalo de madeira" (da mesma forma como na situação em que requisita o lava-pés). ${ }^{17}$

Parece possível compreender, portanto, que Odisseu tenha desejado ser reconhecido por Euricleia. Resta-nos sugerir por que motivo. Ainda que só possamos esboçar uma resposta a essa questão ao final do presente texto, acreditamos não ser de pouca importância a formulação confusa com que Penélope ordena que a serva venha para lavar os pés do estrangeiro. Acompanhando o texto grego - e isso dá uma mostra da importância do suspense para um poema oral como a Odisseia no âmbito de uma performance -, as palavras de Penélope levam a crer que a ordem para Euricleia seria a de lavar os pés de seu... mestre. Mas o que ela afirma, na verdade, refere-se a uma lavagem dos pés do coetâneo de seu mestre [nípson soîo ánaktos homélike] (Od. XIX, 358-9). A dicção confusa de Penélope, contudo, chamou a atenção de grande parte dos comentadores da passagem, os quais justificam o fato das mais diversas maneiras: manipulação, por parte do poeta, das expectativas do público (Russo, 1992, p. 94); jogo linguístico típico da Odisseia (De Jong, 2001, p. 475); reconhecimento dos antigos esposos e acordo tácito sobre a necessidade de informar Euricleia secretamente sobre o novo estado de coisas (Bollack, 2001, p. 238), entre outras. Ainda que essa última suposição de Bollack possa nos parecer extrema, tendemos a ver na formulação do v. 358 mais do que mero jogo linguístico do poeta da Odisseia. Nesse sentido, vale recorrer ao que afirma Austin (1975, p. 221-2):

O ritmo do reconhecimento de Penélope trouxera-lhe quase a identificação sintática do estrangeiro com seu marido (sô̂ ánaktos, v. 358). Esse acidente sintático leva-lhe a divagar diretamente sobre a similaridade entre os dois homens - eles são comparáveis não apenas em termos de idade, mas também de aparência física (vv. 358-9). Então Euricleia entra e continua a linha de pensamento de Penélope, quase como se toda a cena tivesse sido dela. Ela continua a reflexão sobre a similaridade entre os dois homens, primeiro em suas circunstâncias presentes e então em sua aparência física. Aqui mais uma vez a sintaxe

60. Note-se que a menção à fraqueza física de Euricleia e o fato de que ela devesse se levantar para vir até o ponto em que Penélope conversava com o mendigo são indicativos cênicos que tomamos para afirmar que a serva anciã já estava sentada em algum lugar do salão quando Penélope se dirige a ela (Od. XIX, 353-9).

${ }^{17}$ A sugestão foi feita por Duarte (2012, p. 131), que, chamando o reconhecimento pelo qual Odisseu teria sido indiretamente responsável de "aparentemente involuntário", em ambos os casos, não deixa clara a sua opinião: "É curioso perceber aqui semelhanças com o reconhecimento do herói por Euricleia, no canto XIX. Em ambos, Odisseu é indiretamente responsável por seu reconhecimento aparentemente involuntário: no canto VIII, quando pede a Demódoco que cante sua glória, trazendo voluntariamente à baila a lembrança de seu passado; no canto XIX, quando condiciona a oferta de Penélope de que lhe sejam banhados os pés à disponibilidade de uma velha serva para atendê-lo, alguém que seria capaz de reconhecê-lo." 
é um estranho espelho do pensamento, criando as ambiguidades que são tanto os sinais da sua operação mental quanto as ferramentas dessa operação. ${ }^{18}$

E, com efeito, o discurso de Euricleia, valendo-se de uma segunda pessoa do singular não especificada por qualquer marca que identifique aquele a quem o discurso se dirige, justamente por ser um recurso inesperado em Homero, apresenta um leque variado de motivações e implicações possíveis. Acompanhe-se o texto (na tradução de Christian Werner):

"Ai de mim, filho, nada posso fazer por ti, a quem, embora temente ao deus, Zeus abominou entre os homens.

Nunca mortal algum a Zeus prazer-no-raio queimou tantas coxas gordas ou hecatombes seletas quantas tu a ele; com preces ofereceste para atingires idade reluzente e criares o filho ilustre; e agora só de ti tirou de todo o dia do retorno. Assim também dele debocharam mulheres de estranhos longínquos, ao atingir uma casa famosa, como de ti essas cadelas aqui debocharam, todas [...]."

(Od. XIX, 363-72)

Somente ao fim do período (ou, de forma ainda mais precisa, com o fim do período seguinte), sabemos que a segunda pessoa empregada pelo discurso da serva tem como referente o próprio Odisseu. Euricleia dirige-se ao seu antigo mestre acreditando que ele esteja ausente, muito embora o público não ignore que as duas personagens na verdade se encontram face a face.

As interpretações tradicionais dessa passagem chamam atenção para dois pontos: o valor dramático de se postergar a identificação do endereçado pelo discurso de Euricleia - que a princípio poderia muito bem ser o mendigo estrangeiro -, surpreendendo as expectativas do público quando este se revela ser na verdade Odisseu, ou seja, alguém que Euricleia considera ausente da cena (Russo, 1992, p. 94); a ironia dramática contida no reconhecimento, por parte do público, de que alguém considerado ausente por uma das personagens na verdade está presente - ou seja, a ironia instala-se justamente no descompasso entre o que julga saber Euricleia e o que sabe efetivamente o público (De Jong, 2001, p. 476). Essas leituras dão

\footnotetext{
${ }^{18}$ Tradução nossa. No original: “The rhythm of Penelope's recognition had brought her almost to the syntactic identification of the stranger and her husband (sô̂ ánaktos, v. 358). That syntactic accident leads her to muse directly on the similarity between the two men - they are peers not only in age but in physical appearance (vv. 358-9). Then Eurykleia enters and she continues Penelope's line of thought, almost as if the whole scene had been hers. She continues the reflection on the similarity between the two men, first in their present circumstances and then in their physical appearance. Here again syntax is an uncanny mirror of thought, creating the ambiguities that are both the signs of her mental operation and the tools of that operation." (Austin, 1975, p. 221-2).
}

Classica, v. 31, n. 1, p. 9-24, 2018 
conta da superfície do problema das palavras iniciais da serva, mas talvez deixem passar sob silêncio um elemento imprescindível para uma compreensão mais ampla da cena.

Posto que prefiramos não falar de um reconhecimento inconsciente - ou de um tratamento psicológico profundo da cena pelo poeta da Odisseia, através do recurso à ideia de subconsciente ou de conceitos afins ${ }^{19}$ - acreditamos que a proposta de Bollack (2001, p. 240) ofereça hipóteses interessantes para pensarmos o que está em jogo nesse momento:

Através do estrangeiro, Euricleia dirige-se a Odisseu: ele poderia, onde quer que se encontrasse, estar sofrendo os mesmos ultrajes. O infortúnio imerecido os confunde. Um "tu" vale pelo outro. Não há necessidade alguma de se atribuir à linguagem do inconsciente a fusão dos pronomes e das identidades. Não é como se ela deixasse falar seu coração. Mais uma vez aproximamo-nos da identificação, na significância de uma situação: ele, a criança perdida ao longe, é como o mendigo com quem ela ora conversa. Nada os distingue. Eles se parecem como duas ervilhas numa vagem. Euricleia exalta-se porque ela não se contém como Penélope: "jamais algum de todos os estrangeiros que nós vimos, senhores da resistência, se pareceu tanto com ele” (379 sq.). Ela não precisa da cicatriz (que descobrirá em breve) para ter a confirmação do que já sabia. ${ }^{20}$

Ora, essa hipótese de que Euricleia desconfie profundamente da identidade do mendigo estrangeiro - fundamentando-se para isso tanto numa empatia sincera com a situação de penúria do homem ali presente (que, a seus olhos, é também a de Odisseu ausente), quanto num juízo sobre a semelhança física dos dois - parece-nos orientar de maneira interessante uma abordagem possível do significado que o papel da serva desenvolve na trama. Por meio do recurso a uma segunda pessoa não marcada, Euricleia identifica o ausente Odisseu ao homem que se apresenta diante dela.

19 Tal é a abordagem, por exemplo, de Austin (1975, p. 222): "Eurykleia should be addressing the man before her, and syntax helps to promote this idea since Eurykleia omits any name, as if she were continuing a conversation she had already begun. But syntax misleads us: Eurykleia is addressing an absent and unnamed man, from whom Zeus has taken his day of return. Though Eurykleia looks at the stranger, and while looking at him says you, her mind's eye is looking at another Odysseus. Again, in a stroke or two, Homer delineates a fragment of the subconscious."

${ }^{20}$ Tradução nossa. No original: «À travers l'étranger, Euryclée s'adresse à Ulysse; il pourrait, où il est, subir les mêmes outrages. Le malheur immérité les confond. Un « tu » en vaut un autre. Il n'y a aucun besoin d'attribuer au langage de l'inconscient la fusion des pronoms et des identités. Ce n'est pas qu'elle laisse parler son coeur. De nouveau l'on approche de l'identification, dans la signifiance d'une situation : lui, l'enfant perdu au loin, est comme le mendiant à qui maintenant elle parle. Rien ne les distingue. Ils se ressemblent comme deux gouttes d'eau. Euryclée renchérit parce qu'elle ne se retient pas comme Pénélope : « jamais aucun de tous les étrangers que nous avons vus, maîtres de l'endurance, ne lui ressemblait autant» (379 sq.) ; elle n'a pas besoin de la cicatrice, qu'elle va découvrir aussitôt, pour avoir la confirmation de ce qu'elle savait. » (Bollack, 2001, p. 240). 
$\mathrm{Na}$ sequência, a serva muda sutilmente o endereçado que o seu discurso tem em vista - recorrendo ao emprego de um pronome que remete a uma terceira pessoa (keínöi, v. 370) para marcar certa distância do seu mestre ausente - e passa a se dirigir ao mendigo que se encontra diante dela por meio da segunda pessoa (tratamento que ela manterá até o fim do seu discurso: séthen, v. 372; se, v. 376; sý, v. 381). Ainda assim, o estrangeiro permanece sem maiores marcas de distinção na fala que lhe dirige a serva e, nesse sentido, certa confusão permanece e assombrará o emprego da segunda pessoa no discurso de Euricleia até a sua última frase. $^{21}$

De toda forma, o que vale notar é que da identificação (entre Odisseu e o mendigo), tal como inicialmente promovida pelo emprego não especificado da segunda pessoa, passamos a uma comparação entre o destino de Odisseu com a triste situação daquele estrangeiro escarnecido pelas jovens servas. Saímos de uma suspeita que se incorpora no nível linguístico para uma conjectura que se formula de maneira lógica e explícita na fala de Euricleia. ${ }^{22} \mathrm{E}$ a revelação da identidade de Odisseu parece cada vez mais próxima ao público da Odisseia.

Chegando a pouco mais de metade do número total de versos que dura o seu discurso, a serva passa a se dirigir ao mendigo pela primeira vez sem se referir a (ou mencionar diretamente) Odisseu na mesma frase. Trata-se do momento em que ela comenta não ser a contragosto que vai lhe lavar os pés, mas que obedece a um comando de Penélope, ainda que o faça por sua senhora e pelo próprio estrangeiro (referido aqui pelo emprego do termo séthen), posto que movida em seu interior pelo ânimo angustiado (Od. XIX, 374-8). É interessante notar que esse é o único momento do discurso em que Euricleia parece se referir ao estrangeiro como alguém de fato presente e diante dela no momento da cena. Talvez seja por isso que, parando pela primeira vez para contemplá-lo em si mesmo, ela venha a dizer as palavras com que encerra o seu discurso (na tradução de Christian Werner):

$$
\begin{aligned}
& \text { "[...]. Vamos, agora atenta à fala que vou falar: } \\
& \text { já muitos estranhos calejados aqui chegaram, } \\
& \text { mas afirmo nunca ter visto alguém tão parecido } \\
& \text { em corpo, voz e pés, com Odisseu, como pareces tu." }
\end{aligned}
$$

(Od. XIX, 378-81)

\footnotetext{
${ }^{21}$ A sugestão encontra-se no que afirma Austin (1975, p. 222): "When she [Eurykleia] addresses the stranger with second person pronouns and omits any name or title, the effect is to make her initial séo (v. 363) operative through her whole speech, her term of address for both men."

${ }^{22}$ Retenhamos, do que afirma Russo (1992, p. 95), o seguinte: "[...] the interchangeability of their unhappy destinies [is] subtly reinforced by the interchangeability of the second and third persons in Eurycleia's speech." Além disso, talvez valha a pena evocar o que ele afirma na sequência sobre o jogo entre similaridade e identidade nessa passagem do poema: "Now the faithful nurse's statement that the beggar and the absent king have shared similar ill treatment yields the irony that, like Penelope's observation at 358-9, it is truer than the speaker thinks, since their condition and treatment are not similar but identical." (Russo, 1992, p. 95).
}

Classica, v. 31, n. 1, p. 9-24, 2018 
Nesse momento culminante da sua fala, Euricleia compara o mendigo com Odisseu. ${ }^{23}$ Essa inversão do que fizera anteriormente é marca de uma mudança profunda de perspectiva - o discurso deixa de se referir ao presente através do ausente (e, nesse sentido, através do passado), mas se permite uma correspondência direta com o presente em si mesmo (ainda que enquanto termo de uma comparação, ou seja, enquanto meio para uma tentativa de reapresentação do ausente ou de representificação do passado).

Esse é o momento crucial da identificação entre o mendigo e Odisseu: o antigo mestre se faz presente no estrangeiro não apenas por meio da relação anterior de xenía em Creta, nem na semelhança aludida por Penélope entre os seus pés e mãos igualmente envelhecidos (v. 359), mas principalmente no fato de que se pareçam, para além do corpo e dos pés, também na própria voz (v. 381). Esse é o parecer final com que Euricleia encerra de forma certeira a sua tomada de consciência sobre a presença de Odisseu no estrangeiro. ${ }^{24}$ Nesse ponto concordamos com o que afirma Austin (1975, p. 223): “Um momento depois, a cicatriz na perna de Odisseu confirma a sua intuição com evidência documental. É significativo que a cicatriz apareça apenas depois que a percepção de Euricleia já a tenha conduzido até a equação que a cicatriz torna inevitável." ${ }^{25}$

Ora, a construção gradual do discurso da serva obedece a uma lógica à qual aludimos anteriormente, qual seja, à da ring-composition, e que há de ficar clara neste breve resumo dos pontos principais abordados pela fala de Euricleia: i) identificação entre Odisseu e o mendigo, a partir de uma confusão sintática das duas figuras; ii) comparação entre Odisseu e o mendigo, tendo como termo a infelicidade de destino dos dois; iii) referência exclusiva ao mendigo presente na cena e exposição das causas para lhe lavar os pés; iv) comparação entre o mendigo e Odisseu, tendo como termo a semelhança dos dois em corpo, voz e pés. A partir de uma abordagem dessa estrutura tradicional - e que é amplamente difundida na poesia helênica do período arcaico -, fica claro que o termo faltante para o anel fechar-se e retornar ao momento inicial é justamente uma identificação (mas agora entre o mendigo e Odisseu):

\footnotetext{
${ }^{23}$ Comentando os versos 380-1, de Jong (2001, p. 476) afirma o seguinte: "Whereas in 359 Penelope had talked about Odysseus' resemblance to 'the stranger', Euryclea now notes the resemblance of 'the stranger' to Odysseus."

${ }^{24}$ Um ponto interessante para o que tentamos explicitar aqui é a comparação entre o reconhecimento de Telêmaco por Helena (que o deduz a partir da semelhança do jovem com o seu pai), e o reconhecimento de Odisseu por Euricleia. Nas palavras com que Duarte (2012, p. 125) aproxima as duas cenas, apontando a repetição de um mesmo verso nos dois episódios: "Curiosamente, este [o reconhecimento de Telêmaco por Helena] remete a outro dos reconhecimentos de Odisseu, o de Euricleia no livro XIX. A velha ama também nota a semelhança entre o mendigo, cujos pés Penélope lhe pedira para lavar, e Odisseu (Od., XIX, 378-81). Um mesmo verso repete-se, com mínima alteração, nas duas passagens (Od., IV, 141 = XIX, 380): 'Afirmo jamais ter visto uma tamanha semelhança'." ${ }^{25}$ Tradução nossa. No original: "A moment later the scar on Odysseus' leg confirms her intuition with documentary evidence. It is significant that the scar appears only after Eurykleia's perception had already led her almost to the equation that the scar makes inevitable." (Austin, 1975, p. 223).
} 
$\begin{aligned} & \text { i) identificação entre Odisseu e o mendigo; } \rightarrow \text { ii) comparação entre Odisseu e o mendigo; } \\ & \text { iii) referência exclusiva ao mendigo; } \\ & \downarrow \downarrow \\ & \text { v) identificação entre o mendigo e Odisseu; } \leftarrow \text { iv) comparação entre o mendigo e Odisseu; }\end{aligned}$

Ou seja, é natural que um público habituado à forma anelar de pensamento volte as suas expectativas para uma nova identificação entre o mendigo e Odisseu, mas dessa vez não mais tendo como ponto de partida a própria figura ausente - tal como na identificação inicial, cuja medida restringia-se ao antigo rei de Ítaca - e sim a do mendigo presente na cena. Nesse sentido, o que afirmamos com relação às possibilidades de mudança e desenvolvimento no interior de uma estrutura em anel revela-se claramente: o retorno à identificação inicial entre as duas figuras não é mera repetição do mesmo, mas um retorno àquilo que já não pode ser o mesmo justamente porque o caminho para retornar a ele foi responsável por modificá-lo. Euricleia parte de uma figura monolítica de Odisseu - o glorioso rei de Ítaca, jovem e poderoso do seu passado - a partir da qual comparava tudo aquilo que a cercava e, constatando uma presença ínfima e alquebrada de um mendigo estrangeiro, abre-se à possibilidade de cotejar um novo Odisseu, diverso de si mesmo, posto que identificado a partir de um outro. Vê-se que a questão da identidade a partir de uma alteridade é um ponto importante desse discurso da velha serva.

Às palavras certeiras com que Euricleia encerra o seu discurso, o mendigo estrangeiro não tem opção senão aquiescer, afirmando que a semelhança entre ele e Odisseu sempre fora notada pelos seus companheiros. Essa afirmação com que a personagem tenta se proteger, ainda que somada à decisão de se sentar nas sombras, à distância da luz do fogo, não é o bastante para dissipar o clímax construído pelo poema e, a essa altura da cena, o público tem certeza de que uma revelação está a ponto de eclodir (Russo, 1992, p. 95). Odisseu não tem meios para evitar a confirmação da sua identificação por Euricleia, e não deseja fazê-lo, mas toma as medidas necessárias para evitar que essa identificação se torne pública - isso explicaria a sua decisão de ir para um lugar mais discreto e escuro.

Com toda a preocupação que Odisseu demonstra em relação à luz, é o sentido do tato de Euricleia que se mostra crítico nessa situação. Ela encontra a cicatriz quase instantaneamente, não apenas porque já sabia que ela estava lá, mas porque já suspeitara da identidade do mendigo. A sua reação é imediata. (Ahl; Roisman, 1996, p. 233). ${ }^{26}$

Poderíamos fazer uma longa digressão sobre as implicações de marcas que se inscrevem na carne e que permitem a identificação para além de toda e qualquer possibilidade

\footnotetext{
${ }^{26}$ Tradução nossa. No original: “For all Odysseus's management of the lighting, it is Eurycleia's sense of touch that proves critical in this situation. She finds the scar almost instantly, not only because she knew it was there, but because she already suspected the beggar's identity. Her reaction is immediate." (Ahl; Roisman, 1996, p. 233).
}

Classica, v. 31, n. 1, p. 9-24, 2018 
de disfarce, mas vamos nos limitar a uma breve consideração sobre o caso que ora nos ocupa. A cicatriz de Odisseu é uma marca pessoal que, mesmo num período de extrema violência durante o qual cicatrizes desse tipo deveriam ser muito frequentes - seja devido às caçadas, seja devido aos combates -, permite a sua identificação imediata porque está ligada intrinsecamente ao seu passado e ao seu próprio nome. Isso explica uma série de elementos que são incorporados ao poema, na sequência da identificação da cicatriz por Euricleia, e que muitas vezes pareceram estranhos aos intérpretes da Odisseia.

Não pretendemos aprofundar a abordagem desses temas, mas as longas digressões sobre a forma por que Odisseu adquiriu a sua cicatriz - bem como o relato que as precede, no qual se conta que pouco depois que ele nascera, o seu avô materno, Autólico, fora a Ítaca e, tendo recebido a criança dos braços de Euricleia, dera-lhe o nome de Odisseu - fazem parte da resposta à pergunta que nos colocávamos no início do presente texto: por que Odisseu pode ter desejado ser reconhecido por Euricleia?

Os elementos para uma resposta a essa difícil questão acumulam-se em torno de alguns pontos principais: uma tentativa de estabelecer as bases no seu próprio ổkos, dentro de um plano mais amplo para a retomada estratégica do seu espaço como o grande patriarca; uma vontade de recuperação do nome, perdido em suas errâncias por terras ignotas (lembremo-nos, por exemplo, do episódio na caverna de Polifemo, onde literalmente passa a ser chamado de "Ninguém" [Oûtis]), por meio de uma recuperação do significado profundo desse seu nome; um desejo de reconhecimento do seu passado, da sua genealogia e do poder contido em suas raízes familiares. Ora, a figura que reúne a possibilidade de responder a todas essas aspirações é Euricleia.

Ainda que a sua função prática na retomada estratégica de poder por Odisseu, a partir da matança dos pretendentes, não seja primordial, ${ }^{27}$ ela tem de toda forma uma participação ativa no evento, enquanto Penélope deve ser mantida fora da ação (Ahl; Roisman, 1996, p. 233). Além disso, dada a morte anterior da mãe de Odisseu, Anticleia, a única figura maternal que poderia ter presenciado o nascimento da criança e participado ativamente do importante ritual de nomeação seria a de uma velha ama. Nesse sentido, o quiasma que ecoa nos nomes das duas figuras maternais presentes na vida de Odisseu - Anticleia, por um lado, Euricleia, por outro - é representativo do papel que será desempenhado nessa cena pela serva anciã (e que já se encontra em potência quando é dito que ela seria honrada como a própria esposa de Laertes, embora nunca tenha sido tomada num leito por ele, conforme Od. I, 431-2). O kléos [renome] de Odisseu ecoa de forma contrastiva nos nomes de uma e outra (Anticleia podendo ser compreendida como aquela "sem renome", enquanto Euricleia como aquela de "amplo renome").

Apenas levando em conta esses elementos anteriormente mencionados, podemos compreender o longo excurso sobre a nomeação de Odisseu por seu avô Autólico. Trata-se

\footnotetext{
${ }^{27}$ Nesse sentido, Duarte (2012, p. 158) afirma o seguinte: "Euricleia não é uma peça-chave para o acerto de contas entre Odisseu e os pretendentes. A função que lhe cabe, trancar as portas internas e impedir o acesso das mulheres ao salão, estava prevista inicialmente a uma criada indeterminada (Od. XXI, 235-9)."
} 
de um momento fundamental da constituição da identidade do herói, momento em que Euricleia desempenha uma função inusitada e que só faz sentido à luz da sua importância como responsável por identificar o seu antigo mestre e possibilitar que o seu passado fosse reatualizado em meio às dificuldades do presente. Nesse sentido, não é coincidência que Autólico - esse antepassado sagaz e lupino, êmulo de Hermes - seja o responsável por "batizar" Odisseu nas dores da existência. O próprio nome do herói traz as marcas desse momento constitutivo, enquanto o seu corpo porta igualmente os rastros de uma iniciação à coragem e à resistência do verdadeiro guerreiro. ${ }^{28} \mathrm{O}$ papel do avô materno em ambos os casos é fundamental, mas só pode ser atualizado no momento em que se encontra o enredo do poema através da figura da velha ama de Odisseu.

Assim, o sinal de reconhecimento corresponde bem ao grau de intimidade que os personagens mantêm entre si. A cicatriz aparece como o elo que une ama e senhor e, por isso, faz sentido que pertença a esse reconhecimento, não sendo mencionado naqueles que o antecedem. (Duarte, 2012, p. 157).

O reconhecimento de Odisseu por Euricleia é um momento fundamental do nóstos do herói. Depois de ter perdido o nome e a própria identidade em meio a longas errâncias por terras distantes, é preciso que a sua ausência possa ser preenchida paulatinamente no reencontro com as suas verdadeiras raízes no passado, a fim de que se faça mais uma vez presença e plenitude. Nesse sentido, quando Euricleia começa finalmente a ver o presente por meio de um olhar que já não mais se volta unicamente para a ausência do passado, ou seja, quando ela finalmente toca o presente e se dá conta das mudanças trazidas pela passagem do tempo, o mendigo estrangeiro presente é enfim identificado ao poderoso rei de Ítaca ausente e as duas figuras reúnem-se numa só. Um novo Odisseu retorna, mas o seu retorno traz a marca da sua própria diferença.

\section{REFERÊNCIAS}

AHL, Frederick; ROISMAN, Hanna. The Odyssey re-formed. Ithaca; London: Cornell University Press, 1996.

ARISTÓTELES. Poética. Trad. Paulo Pinheiro. São Paulo: Editora 34, 2016.

AUSTIN, Norman. Archery at the Dark of the Moon. Berkeley: University of California Press, 1975.

\footnotetext{
${ }^{28}$ Os apontamentos de Bollack (2001, p. 241) nos ofereceram alguns esclarecimentos importantes acerca dessa questão: «Autolykos était grand voleur, l'émule d'Hermès ; Ulysse lui doit son nom. Odusseus dit la colère ou la révolte (odussaménos), qui supposent toutes deux une coupure, et la méfiance irréductible à l'égard d'Euryclée ; la suspicion est un signe de son identité au même titre que la cicatrice. Dans la maison de son grand-père, il a reçu l'initiation au courage guerrier. La marque qu'il porte est complémentaire de l'héritage d'autonomie, ou si l'on veut, d'insoumission radicale. »
}

Classica, v. 31, n. 1, p. 9-24, 2018 
BEARD, Mary. Thinking in Circles: An Essay on Ring Composition. New Haven; London: Yale University Press, 2007.

BOLLACK, Jean. Le jeu de Pénélope. Europe 865. Homère, p. 218-249, 2001.

DE JONG, Irene. A Narratological Commentary on the Odyssey. Cambridge: Cambridge University Press, 2001.

DUARTE, Adriane da Silva. Cenas de reconhecimento na poesia grega. Campinas: Editora da Unicamp, 2012.

GAINSFORD, Peter. Formal Analysis of Recognition Scenes in the Odyssey. Journal of Hellenic Studies 123, p. 41-59, 2003.

HOMERI Odyssea. Edidit H. van Thiel. New York: Hildesheim, 1991.

HOMERO. Odisseia. Tradução e introdução: Christian Werner. 1. ed. São Paulo: Cosac Naify, 2014.

LEVANIOUK, Olga. Eve of the Festival: Making Myth in Odyssey 19. Hellenic Studies Series 46. Washington: Center for Hellenic Studies, 2011. Disponível em: < http:// nrs.harvard.edu/ urn-3:hul.ebook:CHS_Levaniouk.Eve_of_the_Festival.2011.> Acesso em: 16 abr. 2018.

MURNAGHAN, Sheila. Disguise and Recognition in the Odyssey. Princeton: Princeton University Press, 1987.

RUSSO, Joseph. Books XVII-XX. In: FERNANDEZ-GALIANO, M.; HEUBECK, A.; RUSSO, J. Odyssey vol. III - Books XVII-XXIV. Oxford: Oxford University Press, 1992, p. $1-130$.

THALMANN, William. The Swineherd and the Bow: Representations of Class in the Odyssey. Ithaca; London: Cornell University Press, 1998.

VLAHOS, John B. Homer's Odyssey: Penelope and the case for early recognition. College Literature, p. 135-54, 2011.

WERNER, Christian. O mito do retorno dos heróis de Troia e as funções narrativas dos presságios na Odisseia de Homero. História, imagem e narrativas, n. 12, p. 1-23, 2011. 